\title{
Potret Kekuatan Perempuan Jawa dalam Bingkai Peralatan Tradisional Masyarakat Jawa Pesisir Melalui Analisis Peran Semantis
}

\author{
M. Suryadi \\ Fakultas Ilmu Budaya, Universitas Diponegoro \\ mssuryadi@gmail.com
}

\begin{abstract}
This study is aimed to describe the strength of Javanese women in regulating the rhythms of family life. Strength in the form of tenacity and persistence of Javanese women is captured on the symbol of traditional equipment. The symbol of this equipment is stored in the traditional Javanese kitchen. This symbol contains components of material, function, and Javanese philosophy.

The method of the research was descriptive qualitative, raising the phenomena of traditional equipment in the life of Javanese women. The method of data collection was by observation, in-depth interviews and demonstration activities. The analytical method used in this research was to decompose the components of the lingual units which are aligned on the standard equipment. The method used to explain the menaning was by the semantic equivalent and analogy.

The findings of the research are the novelty of the method, namely the method of interpreting components based on semantic analogies. It was found the strength of Javanese female characters in traditional equipment symbols through understanding concepts and referents. The analysis of the semantic role is able to reveal the relationships of the concepts of the noble values of Javanese culture in the functions of traditional equipment.
\end{abstract}

Keywords: Javanese culture, Javanese women, traditional equipment.

\section{Intisari}

Penelitian ini bertujuan untuk mendeskripsikan kekuatan perempuan Jawa dalam mengatur ritme kehidupan keluarga. Kekuatan dalam bentuk keuletan dan kegigihan perempuan Jawa terpotret pada simbol peralatan tradisonal. Simbol peralatan ini tersimpan dalam dapur tradisional masyarakat Jawa (pawon). Simbol ini memuat komponen bahan, fungsi, dan filosofi Jawa.

Metode penelitian yang digunakan adalah deskriptif kualitatif, mengangkat fenomana peralatan tradisional dalam kehidupan perempuan Jawa. Metode pengumpulan data yang digunakan adalah observasi, wawancara mendalam dan peragaan aktivitas. Metode analisis yang digunakan adalah mengurai komponen satuan-satuan lingual yang melakat pada peralatan terdisional. Piranti atau alat daya urai menggunakan padanan kata dan analogi semantik.

Temuan hasil penelitian adalah kebaruan metode, yakni metode interpretasi komponen berdasarkan analogi semantik. Ditemukan kekuatan karakter perempuan Jawa dalam simbol peralatan tradisional melalui pemahaman konsep dan referentnya. Analisis peran semantic mampu mengungkap keterkaitan konsep nilai luhur budaya Jawa dalam fungsi peralatan tradisional.

Kata Kunci: Kultur Jawa, perempuan Jawa, peralatan tradisional. 


\section{Pendahuluan}

Perempuan Jawa memiliki sejarah panjang dalam babad Jawa. Perempuan Jawa sebagai symbol kelemahan sekaligus symbol kekuatan. Kelemahan bagi laki-laki namun juga kekuatan bagi laki-laki. Keunikan fenomena ini tidak akan kering dalam sejarah penelitian. Perempuan adalah unik. Unik dalam segala aspek kehidupan. Melalui keunikan inilah lahit kekuatan perempuan Jawa. Sejarah mencatat bahwa perempuan Jawa menjadi pemimpin/raja, seperti Tribuwana Wijayatunggaldewi tahun 1325-1351 (Kerajaan Majapahit)(Pratama, Wardani, \& Akbar, 2018), Ratu Shima tahun 1504-1546 (Kerajaan Kalingga) (Hadi, 2010), dan Sri Isyana Tunggawijaya (Kerajaan Medang)(Nusantara, 2010).

Sejarah kekuatan perempuan Jawa menandakan bahwa kesamaan gander antara laki-laki dengan perempuan sudah ada di wilayah Jawadwipa. Fakta ini memperlihatkan bahwa kekuatan dan kepemimpian perempuan Jawa tidak dapat diragukan lagi.

Kekuatan perempuan Jawa dalam ranah keluarga menjadi keunikan fenomena. Salah satu sisi berperan sebagai ibu dari anak-anak dan sisi lain berperan isteri dari sang suami, dan kadang kala berperan sebagai power of man. Keunikan ini perempuan Jawa dapat dikatakan sebagai wonder woman. Multi kekuatan perempuan Jawa inilah yang inspirasi perempuan modern bahwa perempuan Jawa memiliki peran yang sama dalam berbagai ranah, tanpa harus mengabaikan fungsi sejati sebagai seorang ibu yang mempunyai kelembutan perilaku.

Kehebatan kekuatan perempuan Jawa selain terekam melaui sejarah, juga terekam melalui sisi kehidupan yang lekat dengan kehidupan perempuan. Salah satu sisi kehidupan yang lekat dengan dunia femininitas adalah peralatan masak-memasak. Penelusuran kekuatan perempuan Jawa melalui ranah peralatan rumah tangga, khususnya peralatan rumah tangga tradisional, luput dari sorotan. Melalui penlitian ini, akan ditelusuri kekuatan perempuan Jawa melalui keunikan dunia feminine.

Rumusan masalah yang diangkat dalam penelitian ini, bagaimana peran semantik yang melekat pada peralatan tradisional dapat digunakan untuk memotret kekuatan perempuan Jawa dalam kehidupan rumah tangga. 
Kerap kali kedudukan perempuan lebih banyak ditentukan oleh jenis seks dari pada bentuk gandernya. Perempuan Jawa seringkali dipandang posisinya melalui perbedaan seks, sehingga muncul ungkapan kanca wingking, tetapi sangat jarang dpandang sebagai bentuk gander. Perempuan Jawa memiliki ketangguhan di dalam kedudukan sebagai pilar kokohnya rumah tangga posisi ini seyogjanya dipandang sebagai persamaan gander (Mikkola, 2008). Fenomena yang kerapkali muncul bahwa kehebatan dan kesuksesan suami dan anak tidak dapat dilepaskan peran seorang isteri atau perempuan (Slaughter, 2012), dan kedudukan perempuan mulai terangkat dalam publik(Chattopadhyay \& Duflo, 2004) dan (Budiati, 2010).

Kultur Jawa sangat luhur dalam memandang semua aspek kehidupan, termasuk kedudukan perempuan dalam panorama Jawa. Salah satu parameter untuk menjadi sukses bagi ukuran budaya Jawa (Triratnawati \& Triratnawati, 2012). Kesuksesan kerapkali diukur dengan kekuatan ekonomi. Namun dalam budaya Jawa kesuksesan terletak pada penataan harmoni pada diri sendiri. Perempuan Jawa pun memiliki peluang besar untuk mengenbangkan diri selain di ruang domestic, kedudukan perempuan Jawa memiliki peran yang sangat kuat untuk pengembangan diri (Budiati, 2010). Pandangan lain pun kerap muncul antara laki-laki dan perempuan, satu sisi memandangan sebagai perbedaan bilogis/seks, sisi lain memandang sebagai perbedaan gender (Hermawati, 2007).

Peralatan dapur tradisional merupakan alat atau perkakas masak-memasak yang dimiliki oleh masyarakat di wilayah nusantara yang diturunkan secara turun temurun, begitu juga dengan masyarakat Jawa. (Mairida, Hariadi, \& Saudagar, 2014). Peralatan dapur tradisional ini memiliki sejarah yang cukup panjang, sepanjang sejarah manusia itu sendiri (Suranny, 2014). Pembuatannya pun memiliki proses yang cukup panjang dan setiap alat memiliki karakter yang berbeda-beda, sehingga keberadaanya pun perlu dilestarikan (Suryadi, 2018).

Analisis peran semantik yang dimanfaatkan penelitian ini untuk mempertajam analisis adalah semantik leksikal (Nugues, 2014) yang memperkenal semantik kognitif, yang dapat dimanfaatkan memahami korelasi antara bentuk dengan arti yang ditimbulkan oleh bentuk itu sendiri, sehingga dapat dipotret secara utuh. Semantik leksikal pun ditawarkan oleh (Geeraerts, 2009) untuk memahami bentuk-bentuk leksikon yang dikesinambungkan terhadap arti yang ditimbulkan secara komprehensif. Teori semantik 
lainnya yang dimanfaatkan untuk membedah peran semantic yang melekat pada leksikon peralatan rumah tangga tradisional adalah (Partee, 1994: 16), (Bisetto, 1997:12), dan (Fillmore, 2006: 35).

\section{Metode Penelitian}

Penelitian ini menggunakan ancangan sosioetnolinguistik, menekankan gejala sosial pada masyarakat Jawa Pesisir, melalui peran perempuan Jawa dalam kehidupan berumah tangga. Peran perempuan Jawa tersebut diproyeksikan dengan simbol peralatan tradisional yang tersimpan dalam tradisi masak-memasak di pawon. Dengan demikian, jenis penelitian pada kajian ini adalah kualitatif. Metode penelitian yang diterapkan menggunakan tiga urutan, yakni metode penyadiaan data (Sudaryanto, 1993b), dilanjutkan dengan metode analisis, dan difinalisasi dengan metode penyajian hasil analisis data (Sudaryanto, 1993a).

Metode pengumpulan data yang digunakan dalam penelitian ini adalah metode survey, metode observasi, metode wawancara, dan metode pemotretan objek. Keempat metode ini memiliki peran yang saling melengkapi untuk memperoleh kecukupan data dalam analisis. Metode survey dilakukan untuk menjaring lokasi penelitian yang diduga masih menyimpan dan menggunakan peralatan rumah tangga tradisional. Melalui survey inilah akan ditetapkan tempat penelitian, yang sekaligus ditentukan titik pengamatan yang memiliki kekayaan data penelitian. Metode obsrvasi dimanfaatkan untuk menjaring data di titik penelitian. Semua informasi yang terkait dengan data diupayakan optimal kebenarannya, sehingga dalam metode observasi ini akan dipilih informan-informan yang mengetahui benar kegunaan, fungsi, dan nilai filosofi yang terkait dengan peralatan rumah tangga tradisional. Metode wawancara yang digunakan adalah wawancara mendalam dengan struktur yang sudah dimantapkan pada saat observasi dilakukan. Kegunaan metode wawancara adalah menggali informasi secara detail semua komponen yang diperlukan dalam penelitian, dengan demikian semua informasi data dapat terpenuhi secara optimal pada metode wawancara. Metode pemotretan objek digunakan untuk menggali relasi kemanfaatan data terhadap nilai fungsi yang masih relevan dengan kehidupan perempuan Jawa, baik secara ukuran diakronis maupun sinkronis.

Data yang diperoleh akan dikaji dengan memperhatikan satuan lingual yang melekat pada perkakas tradisional dipilahkan antara satuan bentuk dan arti. Pada satuan bentuk diperoleh dua komponen dasar, yakni etima dan konsep. Kedua komponen tersebut 
dikorelasikan dengan referen dan fungsinya. Fungsi yang dimiliki akan direkonstruksi dengan memanfaatkan nilai budaya yang melekat pada jiwa luhur perempuan Jawa sehingga dapat dibidik potret kekuatan perempuan Jawa masa kini yang terukir pada masa lalu. Proses analisis tersebut akan menggunakan metode pemilihan unsur bentuk dan arti, dengan memanfaatkan metode padan membandingkan yang selaras antara komponen pendukungnya (Sudaryanto, 1993a).

Metode penyajian hasil analisis mengunakan metode penyajian informal, yakni semua hasil analisis yang diperoleh akan dideskripsikan secara linear dengan memanfaatkan urutan yang jelas dan logis. Penyajian ini menghindari bentuk-bentuk lambang dan numerik.

\section{Hasil dan Pembahasan}

Perempuan Jawa adalah lambang kelemahlembutan sekaligus sebagai simbol kekuatan. Perempuan Jawa sebagai lambang kelemalembutan manakala dipotret dari segi perilaku dan sikap. Sikap yang selalu melekat pada perempuan Jawa adalah santun, sederhana, tekun, manut, anggun, sabar, telaten, mengalah, dan ramah.

Perempuan Jawa memiliki perilaku santun. Santun dalam berperilaku dan santun dalam bertutur. Dua perilaku tindakan tersebut sudah diajarkan dan ditanamkan sejak kecil. Perempuan Jawa kalau tertawa tidak tampak giginya, kalau berjalan tidak terdengar terompaknya, dan kalau makan tidak terdengar dentingan sendok dan piringnya. Kesantunan tutur pada perempuan Jawa diwujudkan dengan bertutur lemah lembut, tidak suka menyela pembicaraan, tidak suka menghardik atau berbicara keras, sehingga dapat dianalogikan tuturan perempuan Jawa selembut tembangnya.

Perempuan Jawa memiliki sifat sederhana. Sederhana bagi konsep budaya Jawa adalah mensyukuri apa yang telah dimilikinya, sebagai hasil dari upaya kegiatan dan pekerjaannya. Perempuan Jawa tidak banyak menuntut yang bukan haknya, lebih bersikap menyukupkan apa yang sudah dimiliki. Konsep sederhana yang melekat pada perempuan Jawa inilah yang selalu membuat suasana rumah tangga, menjadi sejuk dan surganya suami dan anak-anaknya.

Ramah adalah bagian sikap yang melekat pada perempuan Jawa. Ramah adalah mudah tersenyum dan bermuka seri. Indah dilihat dan menyejukkan hati. Ramah pada 
konsep perempuan Jawa adalah selalu menghargai suami, orang tua, dan tauladan bagi anak-anaknya. Sikap inilah sebagai tonggak kuatnya pilar rumah tangga. Perempuan Jawa tetap tersenyum walaupun hati sedih, tetap tersenyum walaupun ada beban berat di hatinya, tetap senyum walaupun hatinya menangis. Kekuatan menyimpan rasa untuk tetap tersenyum inilah perilaku ramah seoarang perempuan Jawa.

\section{Potret Kekuatan Perempuan Jawa}

Kekuatan pereampuan Jawa tercermin dalam sikap, pemikiran, dan pendirian. Kekuatan perempuan Jawa terletak di tengah kelembutan. Fenomena inilah letak keunikan perempuan Jawa. Ditengah perilaku yang lemah lembut terdapat jiwa dan pemikiran yang kuat, bahkan kekuatan jiwa perempuan lebih kuat dibandingkan laki-laki. Hal ini terlihat pada ungkapan Jawa sayektine wong wedok luwih kuwat tinimbang wong lanang, kuat nyimpen ati, kuat ngadekake ceting, lan kuat nganterake anak-anake dadi wong 'sebenarnya seorang wanita lebih kuat dibandingkan seorang laki-laki, yakni kuat menyimpan rahasia keluarga, kuat berbuat adil dalam keluarga, dan kuat mengantarkan anak-anaknya menjadi sukses'. Ungkapan ini memiliki isyarat kuat, bahwa dibalik sikap lemah lembut terdapat kepribadian yang kuat.

Kekuatan perempuan Jawa juga tampak dalam keuletan dan kegigihan di dalam pengaturan tata rumah tangga maupun kehidupan sosial di luar ranah keluarga, kuat pada ranah sosial dan politik atau kepemimpinan publik. Kekuatan perempuan Jawa tampak sekali dalam ranah keluarga, pada saat berperan mengatur tatanan keluarga, yakni membuat cukup rejeki yang diberikan suami, menata keuangan untuk kebutuhan seharihari, membagi waktu untuk suami dan anak, menutupi kekurangan kebutuhan. Semua kekuatan tersebut tersimbol pada nilai-nilai kultur yang ada dalam kehidupan masyarakat Jawa. Beberapa simbol yang membuat perempuan Jawa kuat, sebagai berikut.

(1) Nadhahi beras kucar-kucur ning klasa kara tangan loro

'Menerima apa yang diberikan suami (rejeki/beras) dengan rasa syukur'

(2) Nyimpen dhuwit ning kendhit

'Menjaga dengan amanah rejeki/penghasilan suaminya'

(3) Gandheng bojo mangku anak

'Mampu mebuat bahagia suami dan anak-anaknya'

(4) Gelem nandhur lan macul 
'Mau membantu kerja suami untuk memenuhi kebutuhan sehari-hari'.

Ungakapan-ungkapan luhur dalam kearifan lokal tersebut sebagai isyarat bahwa perempuan Jawa sebagai perempuan cantik dengan kekuatan super woman.

\section{Potret Kekuatan Perempuan Jawa dalam Bingkai Peralatan Tradisional}

Potret kekuatan perempuan Jawa terekam dalam peralatan tradisional. Perekaman tersebut tampak dalam simbol-simbol yang melekat pada peralatan tradisional. Dalam kultur budaya Jawa, sesuatu yang melekat pada identitas diri memiliki pertalian sejarah dan keluhuran nilai. Dengan demikian, semua penamaan identitas yang melekat pada sesuatu barang, termasuk peralatan tradisional dapat ditelusuri rentetan historisnya (diakronis) yang diproyeksikan dengan perwatakan penggunanya. Pada kajian ini, dapat dibuat skema yang cukup unik, dengan mengadobsi teori urutan semantik pada leksikal semantik.

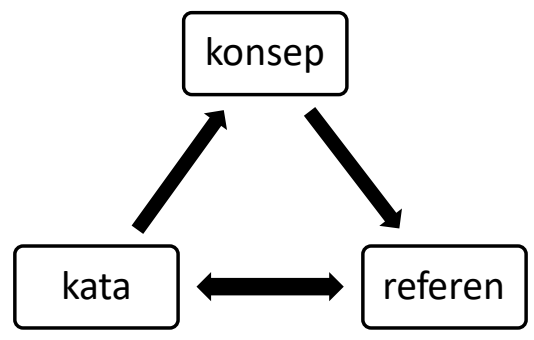

Rekonstruksi Penelusuran Potret Perempuan Jawa

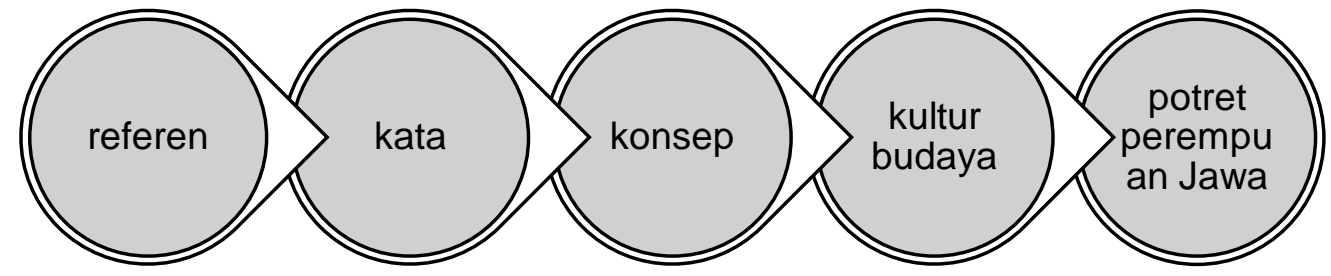

Bentuk leksikon peralatan rumah tangga tradisional masyarakat Jawa pesisir yang memproyeksikan kekuatan perempuan Jawa, dapat dilihat pada peralatan dapur parut, lading, cowek.

\section{Leksikon Parut}


Leksikon parut memiliki arti alat untuk mengukur kelapa, wortel, jejamuan, dan sebagainya dibuat dari bahan papan yang berpaku kawat banyak. Referen yang dibentuk adalah sepotong kayu papan ukuran lebar segenggam tangan, panjang/ setinggi lengan bawah, berpaku baris kawat tajam. Konsep yang ditimbulkan dari referen parut dalam masyarakat Jawa adalah pengerut kelapa dan jejamuan. Melalui konsep ini fungsi perkakas parut adalah mengerut kelapa dan jejamuan agar dapat diolah menjadi bagian dari masakan. Nilai filosofis yang ditimbulkan dari leksikon parut adalah kekuatan dan ketajaman, sehingga perkakas ini selalu disimpan di tempat tinggi agar terhindar dari jangakauan anak-anak. Perkakas parut di ruang pawon selalu di tempatkan glodog atau pogo. Nilai filosofi ini sebagai potret kekuatan perempuan Jawa untuk mengubah sesuatu kehidupan menjadi lebih bermanfaat, waulaupun saat mengubah menjadi sebuah kebaikan harus melalui laku yang menyakitkan (diparut). Namun, hasil akhirnya adalah sebuah kebaikan yang dapat dinikmati oleh semua anggota keluarga.

\section{Leksokon Lading}

Leksikon lading (pisau) adalah sebilah besi tipis dan tajam bagian bawah, bertangkai kayu untuk genggaman tangan. Lading digunakan sebagai pisau dapur untuk mengiris sayuran, bumbu, dan daging. Referen lading dideskripsikan sebagai pisau dapur alat untuk memotong sayur dan mencincang daging. Konsep yang muncul dalam leksikon lading adalah pemotong sayur dan daging. Nilai filosofi yang muncul dalam kultur Jawa, sebagai berikut.

Lading iku kudhu landep, landhepe lading ngaluske rajangan 'pisau dapur itu harus tajam, tajamnya pisau menghaluskan atau merapikan irisan'. Ungkapan ini mengandung nilai kearifan bahwa ketajaman sebuah pisau harus memberi manfaat yang paling baik, apa yang disebabkan oleh tindakan sebuah pisau harus menghasilkan sesuatu yang lebih baik dan manfaat. Nasihat yang diberikan bahwa tajamnya sebuah ucapan harus menghasilkan sebuah kebaikan atau kemanfaatan.

Lading iku landepe ning ngisor 'pisau itu tajamnya bagian bawah'. Ungkapan ini memiliki pesan kearifan bahwa tajamnya nasihat harus diutamakan pada anak-anaknya, sedangkan kelembutan diperuntukkan pada suami dan orang tuanya. Nasihat yang disematkan dalam simbol lading bahwa kehidupan dalam rumah tangga harus terjadi pembagian ranah yang tepat. 
Referen lading dalam kehidupan masyarakat Jawa pesisir sebagai kekuatan perempuan Jawa dalam membina rumah tangga harus empan papan, tahu menempatkan diri, yakni dapat memilah-milah kapan harus berhadapan dengan suami, kapan berhadapan dengan orang tua, dan kapan berhadapan dengan anak. Kemampuan menempatkan diri inilah mencerminkan ketajaman sebuah lading. Bertindak tegas dengan sang anak, bertindak lemah lembut terhadap suami dan orang tua.

\section{Leksikon Cowek}

Leksikon cowek (cobek) memiliki arti sebuah piring dari bahan batu atau bahan tanah untuk menggiling cabai dan bumbon. Referen cowek digambarkan sebagai piring tebal berbahan dasar batu atau tanah, sebagai tempat untuk melumatkan bumbon dan sambal. Konsep yang dimuat dalam leksikon cowek adalah pelumat bumbon dan sambal. Nilai kultur budaya Jawa yang ditimbulkan oleh konsep cowek adalah kemampuan menahan gerusan, cobaan, dan sekaligus sebagai bentuk ketabahan. Hasil ketabahan ini menghasilkan jiwa yang kokoh dan kemanfaatan yang tinggi. Beberapa ungkapan yang memiliki nilai keluhuran yang terkait dengan nilai filosofi cowek, sebagai berikut.

Kuate uleg-uleg ora sanggup mecahke cowek 'kuatnya alu tidak sanggup memecahkan cobek'. Keluhuran ungkapan ini memberikan nasihat bahwa kuatnya terpaan, kuatnya cobaan hidup bagi perempuan Jawa tidak akan mematahkan semangatnya, justru sebaliknya akan menempa jiwanya semakin kokoh dan kuat.

Kawake cowek dadi aluse pipi 'lawas/tuanya cobek menjadi halusnya piringan cobek'. Keluhuran yang dinyatakan pada ungkapan tersebut adalah seiring semakin banyak tempaan, seiring pula pengalaman hidupnya, semakin tambah dewasa dan semakin bijak (halus) dalam mengambil keputusan.

Potret perempuan Jawa yang dapat diperoleh dari simbol cowek adalah kekuataan perempuan Jawa dalam menyikapi beratnya kehidupan. Seorang ibu yang bijak manakala salah satu diukur dari lamanya kehidupan rumah tangganya di samping usia biologisnya. Perempuan Jawa akan semakin bijak atau halus dalam mengambil keputusan terhadap persoalan. Kerapkali dalam kehidupan keluarga Jawa manakala sang suami akan mengambil keputusan selalu minta pertimbangan sang isteri.

\section{Simpulan}


Kekuatan karakter perempuan Jawa terbentuk melalui embrio kultur budaya Jawa yang telah dikenalkan dan diajarkan sejak kecil. Tatanan budaya Jawa Yang dikenalkan melalui fungsi peralatan rumah tangga membentuk karakter perempuan Jawa yang lemah lembut namun memiliki keperibadian yang kuat.

Kekuatan karakter perempuan Jawa terpotret dalam nilai-nilai kearifan yang melekat pada peralatan rumah tangga tradisional. Rekonstruksi penelusuran karakter perempuan Jawa melalui kekauatan analisis peran semantic. Melalui kekuatan peran semantik yang mengadopsi kekuatan teori semantik leksikal yang dipadukan dengan kultur budaya Jawa maka ditemukan rangkaian analisis yang berurutan: referen-kata-konsepkultur budaya-potret kekuatan leksikon.

\section{Daftar Pustaka}

Bisetto, A. 1997. The Generative Lexicon. Lingua e Stile.

Budiati, A. C. 2010. Aktualisasi Diri Perempuan Dalam Sistem Budaya Jawa (Persepsi Perempuan terhadap Nilai-nilai Budaya Jawa dalam Mengaktualisasikan Diri). Pamator.

Chattopadhyay, R., \& Duflo, E. 2004. Women as policy makers: Evidence from a randomized policy experiment in India. Econometrica. https://doi.org/10.1111/j.14680262.2004.00539.x

Fillmore, C. J. 2006. Frame Semantics. In Encyclopedia of Language \& Linguistics. https://doi.org/10.1016/B0-08-044854-2/00424-7

Geeraerts, D. 2009. Theories of Lexical Semantics. https://doi.org/10.1093/acprof:oso/9780198700302.001.0001

Hadi, M. 2010. Ratu Kalinyamat. yogyakarta: Pustaka Sastra.

Hermawati, T. 2007. Komunikasi Massa. Budaya Jawa Dan Kesetaraan Gender. https://doi.org/10.1111/j.1523-1739.2010.01600.x

Mairida, D., Hariadi, B., \& Saudagar, F. 2014. Kajian Etnobotani Peralatan Rumah Tangga Suku Anak Dalam di Taman Nasional Bukit Dua Belas Kabupaten Sarolangun, Jambi Etnobotany. Biospecies.

Mikkola, M. Hu-B. 2008. Feminist Perspectives on Sex and Gender. Stanford Encyclopedia of Philosophy Feminist Perspectives on Sex and Gender.

Nugues, P. M. 2014. Lexical semantics. In Cognitive Technologies. https://doi.org/10.1007/978-3-642-41464-0_15

Nusantara, T. W. 2010. Pu Sindok Sri Isanawikramma Dharmmotunggadewa, Pendiri Kerajaan Medang i Bhumi Mataram i Watugaluh.

Partee, B. H. 1994. Lexical Semantics and Compositionality. In Invitation to Cognitive 
Science, Part I: Language.

Pratama, D., Wardani, W. G. W., \& Akbar, T. 2018. Designing Visual Novel Characters of Gajah Mada and Tribhuwana Tunggadewi as Representation of History Figures. Humanus. https://doi.org/10.24036/humanus.v17i1.9824

Slaughter, A.-M. 2012. Why Women Still Can't Have It. The Atlantic.

Sudaryanto. 1993a. Metode dan aneka teknik analisis bahasa: pengantar penelitian wahana kebudayaan secara linguistis. yogyakarta: Duta Wacana University Press.

Sudaryanto. 1993b. Metode dan Aneka Teknik Pengumpulan Data. yogyakarta: Gajahmada University Press.

Suranny, L. E. 2014. Alat Pertanian Tradisional Sebagai Warisan Kekayaan Budaya Bangsa. Jurnal Arkeologi Papua.

Suryadi, M. 2018. Nilai Filosofis Peralatan Tradisional Terhadap Karakter Perempuan Jawa dalam Pandangan Masyarakat Pesisir Utara Jawa Tengah. Nusa: Jurnal Ilmu Bahasa Dan Sastra. https://doi.org/10.14710/nusa.13.4.567-578

Triratnawati, A., \& Triratnawati, A. 2012. Konsep Dadi Wong Menurut Pandangan Wanita Jawa. Jurnal Humaniora. https://doi.org/10.22146/jh.v17i3.855 